\title{
BENZOIC ACID DERIVATIVES AS EFFECTIVE CORROSION INHIBITORS FOR CARBON STEEL IN $3.5 \%$ SODIUM CHLORIDE SOLUTION.
}

\author{
Nour. E.A.Abdel-satar ${ }^{1}$ A.S.Fouda ${ }^{2}$ E.M.Khalil ${ }^{3}$ Gamal A.EL-Mahdy ${ }^{3}$ Ahmed S.Mohamed $^{4}$ \\ 1. Chemistry Department, Faculty of Science, Ain Shams University, Cairo, Egypt \\ 2., Chemistry Department, Faculty of Science, Mansoura University, Mansoura-35516, Egypt \\ 3. Chemistry Department, Faculty of Science, Helwan University, Helwan, Cairo, Egypt \\ 4. Refining and Processing Department, Egyptian general petroleum corporation, Cairo, Egypt
}

\begin{abstract}
New corrosion compounds were prepared based on acryloyl chloride and the efficiency of the prepared compounds to inhibit carbon steel (CS) corrosion in 3.5\% sodium chloride solution were studied through different electrochemical techniques [potentiodynamic polarization (PP), electrochemical impedance spectroscopy (EIS) and electron frequency modulation (EFM)] and Quantum chemical calculations. The results showed that the investigated compounds are working as good corrosion inhibitor compounds, the inhibition efficiency (\%IE) increases as the compound concentration increase. The polarization data revealed that these compounds act as cathodic and mixed type compounds and are adsorbed on CS surface following Langmuir adsorption isotherm.
\end{abstract}

Keywords: carbon steel, sodium chloride solution and corrosion inhibitor compound

\section{INTRODUCTION}

Corrosion is a material degradation caused by the chemical reaction with other materials and/or the environment [1]. This process often occurs in the industry of a material oil and gas. In the industrial field, Carbon steel plays an important role in a lot of industries specially oil and gas industry [2-5] it is the most widely used engineering material accounts for approximately $85 \%$ of the annual steel production worldwide. Carbon steel corrosion in oil and gas industry is a significant problem as it affects not only the production`s stability but it also causes economic loss. Organic compounds containing heterocyclic atom is the most widely used corrosion compounds [6-8]. $\mathrm{O}, \mathrm{N}$ and/or $\mathrm{S}$ atoms present in the prepared acryloyl derivatives increase the possibility to use it as corrosion compound [9-12] due to overlapping of $\mathrm{P}$ orbital of hetero atoms with vacant d orbital of metal [13-21]. It can also be said that the compound forms protective layer on the metal surface by the reaction between the solution and the corroded metal surface [22].Different electrochemical techniques were applied to study the efficiency of the prepared compounds (compound 1 and compound 2) to prevent carbon steel corrosion in $3.5 \% \mathrm{NaCl}$ solution.

\section{MATERIALS AND SOLUTIONS}

\subsection{Materials}

The compositions of commercial C steel are as of weight $\% 0.200 \mathrm{C}, 0.91 \mathrm{Mn}, 0.007 \mathrm{P}$, $0.002 \mathrm{Si}$ and the rest is $\mathrm{Fe}$

\subsection{Solutions}

2.2.1.Acryloyl chloride

2.2.2. Sodium chloride solution $3.5 \%$ Corrosion solution was attained by mixing 35.24 grams of $\mathrm{NaCl}$ and 1000 $\mathrm{mL}$ distilled water to get $\mathrm{NaCl} 3.5 \%$.

2.2.3.The synthesized acryloyl derivatives studied and tested as corrosion compounds with molecular formula and molecular weight are shown as follow.

\section{EXPERIMENTAL}

\subsection{Chemistry:}

The infrared spectra were recorded using potassium bromide disks on a Pye Unicam SP- 
3-300 infrared spectrophotometer, the established values of the gas phase frequencies are given between brackets. ${ }^{1} \mathrm{HNMR}$ spectra were run at $300 \mathrm{MHz}$, on a Varian Mercury VX-300 NMR spectrometer and Brukeravance III $400 \mathrm{MHZ}$, using TMS as an internal standard in deuterated dimethylsulphoxide. All the spectral measurements were carried out at the NMR laboratory of the Ministry of Defence Chemical Laboratories, Egypt, at the Micro Analytical Centre of Ain Shams University, Egypt. All the chemical reactions were monitored by TLC.

\subsubsection{General method for preparation of compounds 1 and 2}

Stirring (0.1 mole) of acryloyl chloride with (0.1 mole) of ammonium thiocyanate in dry acetone $(50 \mathrm{ml})$ for 20 minutes then filter the mixture to remove ammonium chloride, Then reflux the prepared acryloyl thiocyanate mixture with (0.1 mole) of 2-aminobezoic acid and 4-amino benzoic acid respectively for one hour, pour the solution and evaporate the excess acetone the formed ppt was filtered off, dried.

\subsubsection{2-(3-acryloylthioureido)benzoic acid. compound 1}

Yield 85 \%; yellow semisolid; IR (KBr) broad band at $3494 \mathrm{~cm}^{-1}\left(\mathrm{v}_{\text {он }}\right), 3378,3128 \mathrm{~cm}^{-}$ ${ }^{1}\left(v_{\mathrm{NH}}\right), 1715,1691 \mathrm{~cm}^{-1}\left(\mathrm{v}_{\mathrm{C}=\mathrm{O}}\right) .{ }^{1} \mathrm{HNMR}(300$ MHz, DMSO-d ${ }_{6}$ ): $\delta \mathrm{H}$ (ppm) 5.9 (d, 2H, olefinic $\left.\mathrm{CH}_{2}\right), 6.5(\mathrm{t} .1 \mathrm{H}$, olefinic $\mathrm{CH}), 7.4-7.8(\mathrm{~m} .4 \mathrm{H}$, Aromatic), 11.2, 11.8 (s, 2H, $\mathrm{D}_{2} \mathrm{O}$ exchangeable 2NH), 12 (s, $1 \mathrm{H}, \mathrm{D}_{2} \mathrm{O}$ exchangeable $\mathrm{OH}$ ). Anal. Calculated for $\mathrm{C}_{11} \mathrm{H}_{10} \mathrm{~N}_{2} \mathrm{O}_{3} \mathrm{~S}$ (250.04): C, 52.79;

\section{(3-acryloylthioureido)benzoic acid. compound 2}

Yield 89 \%; orange semisolid; IR (KBr) broad band at $3444 \mathrm{~cm}^{-1}(\mathrm{~V} \mathrm{OH}), \quad 3352,3152 \mathrm{~cm}^{-}$ ${ }^{1}\left(\mathrm{v}_{\mathrm{NH}}\right), 1721,1681 \mathrm{~cm}^{-1}\left(\mathrm{v}_{\mathrm{C}=\mathrm{o}}\right) .{ }^{1} \mathrm{HNMR}$ (300 MHz, DMSO-d $\mathrm{d}_{6}$ ): $\delta \mathrm{H}$ (ppm) 6.3 (d, 2H, olefinic $\left.\mathrm{CH}_{2}\right), 6.9$ (t.1H, olefinic $\mathrm{CH}$ ), 7.3-7.9 (m.4H, Aromatic), 11.3, 11.5 (s, 2H, $\mathrm{D}_{2} \mathrm{O}$ exchangeable 2NH), 12.0 (s, $1 \mathrm{H}, \mathrm{D}_{2} \mathrm{O}$ exchangeable $\mathrm{OH}$ ). Anal. Calculated for $\mathrm{C}_{11} \mathrm{H}_{10} \mathrm{~N}_{2} \mathrm{O}_{3} \mathrm{~S}$ (250.04): C, 52.79; H, 4.03; N, 11.19; Found: C, 54.92; H, 4.32; N, 11.50 .

\subsection{Corrosion inhibition tests}

$3.5 \%$ sodium chloride solution, Corrosion solution was attained by mixing 35.24 grams of $\mathrm{NaCl}$ and $1000 \mathrm{~mL}$ distilled water to get $\mathrm{NaCl}$ $3.5 \%$. Then preparation of the working solution with the tested compounds with a concentration ranges from $25 \mathrm{ppm}$ to $150 \mathrm{ppm}$ for each compound. All solution were prepared using distilled water.

\subsubsection{Electrochemical measurements}

Three different electrochemical techniques were applied to study the corrosion characteristics of carbon steel in $100 \mathrm{ml}$ of 3.5 $\% \mathrm{NaCl}$ in presence and absence of investigated compounds, all of these techniques were performed at $25{ }^{\circ} \mathrm{C}$ using three electrode systems present in a glass cell in which a specimen of carbon steel with area equals to 1 $\mathrm{cm}^{2}$ act as working electrode and saturated calomel electrode (SCE) act as reference electrode and counter or auxiliary electrode from platinum. The working electrode is prepared by welding the carbon steel specimen 
BENZOIC ACID DERIVATIVES AS EFFECTIVE CORROSION ...

with copper rod from one side and perfectly encapsulated into a glass rod so that one face of carbon steel was left to expose the test solution. before starting the experiments the carbon steel specimen is mechanically abraded with emery papers (a coarse paper was used initially and then progressively finer Grades up to 2000 grit size) and degreased using acetone then rinsed with bidistilled water then finally dried between filter paper. Results obtained from electrochemical techniques were utilized by Gamry Instrument (PCI4/750) with a computerized frameworks contain DC105 software for potentiodynamic polarization measurements, EIS300 software for electrochemical impedance (ac) spectroscopy, and EFM140 software for electrochemical frequency modulation techniques. In addition to using Echem Analyst 6.03 software for data fitting, graphing and plotting.

\subsubsection{Potentiodynamic polarization (PP) measurements}

Tafel polarization slopes were obtained through changing the electrode potential automatically from (-0.5 to $0.5 \mathrm{~V}$ vs. SCE) [23] at open circuit potential (OCP) with a scan rate of $1 \mathrm{mVs}^{-1}$. The corrosion current is performed by extrapolation of anodic and cathodic Tafel lines to a point which gives $\log \mathrm{i}_{\text {corr }}$ and the corresponding corrosion potential ( $\left.\mathrm{E}_{\text {corr }}\right)$ for compound free solution and for each concentration of compound.inhibition efficiency (\%IE) and surface coverage $(\theta)$ can be calculated using $i_{\text {corr }}$ as shown in equation (1)

$\%$ I E $=100 \times \theta=\left[1-\left(\mathrm{i}_{\text {corr }} / \mathrm{i}_{\text {corr }}{ }^{\circ}\right)\right] \times 100$

Where $\mathrm{i}_{\text {corr }}$ and $\mathrm{i}_{\text {corr }}{ }^{\circ}$ are corrosion current densities in presence and absence of the tested compounds respectively.

\subsubsection{Electrochemical impedance spectroscopy (EIS) measurements}

Kinetics of electrochemical processes and capacitive behaviour of investigated compounds on carbon steel were characterized by EIS measurements at open circuit potential and in a frequency range from $100 \mathrm{kHz}$ to 0.5 $\mathrm{Hz}$. Charge transfer resistance obtained from EIS data used to calculate inhibition efficiencies (\%IE) and surface coverage $(\theta)$ as shown in equation (2)

$\% \mathrm{IE}=100 \times \theta=\left[1-\left(\mathrm{Rct}^{\circ} / \mathrm{Rct}\right)\right] \times 100$

Where Rct ${ }^{\circ}$ and Rct are the charge transfer resistance in absence and presence of the tested compounds respectively.

\subsubsection{Electrochemical frequency modulation (EFM) measurements}

Two frequencies 2 and $5 \mathrm{~Hz}$ and base frequency $0.1 \mathrm{~Hz}$ were used to obtain intermodulation spectra of the electrochemical frequency modulation. The larger peaks were used to calculate the corrosion current density (icorr), the Tafel slopes ( $\beta$ c and $\beta a$ ) and the causality factors CF-2 and CF-3. The obtained values of icorr are used to calculate inhibition efficiencies (\%IE) and surface coverage $(\theta)$ as shown in equation 3 :

$\%$ I E $=100 \times \theta=\left[1-\left(\mathrm{i}_{\text {corr }} / \mathrm{i}_{\text {corr }}{ }^{\circ}\right)\right] \times 100$

Where $\mathrm{i}_{\text {corr }}$ and $\mathrm{i}_{\text {corr }}{ }^{\circ}$ are corrosion current densities in presence and absence of the tested compounds respectively.

\section{Quantum Chemical Calculations.}

The molecular structures of the investigated compounds were optimized with PM3 semi empirical method. All the quantum chemical calculations were performed with Spartan 10 V1.10.

\section{RESULTS AND DISCUSSION}

\subsection{Chemistry}

The reaction of acryloyl chloride with ammonium thiocyanate by stirring in dry acetone for half an hour followed by refluxing the prepared mixture with 2-aminobezoic acid and 4-amino benzoic acid respectively for one hour the prepared compound accompanied with appearance of $2 \mathrm{v}_{\mathrm{C}=\mathrm{O}}$ as well as appearance of broad band attributed to presence of $\mathrm{COOH}$ this improve the formation compound $1, \mathrm{~B}$ respectively which they are not soluble in water so we add $\mathrm{Na}_{2} \mathrm{CO}_{3}$ to convert it to soluble salt (scheme 1).

\subsection{Potentiodynamic polarization (PP) measurements}




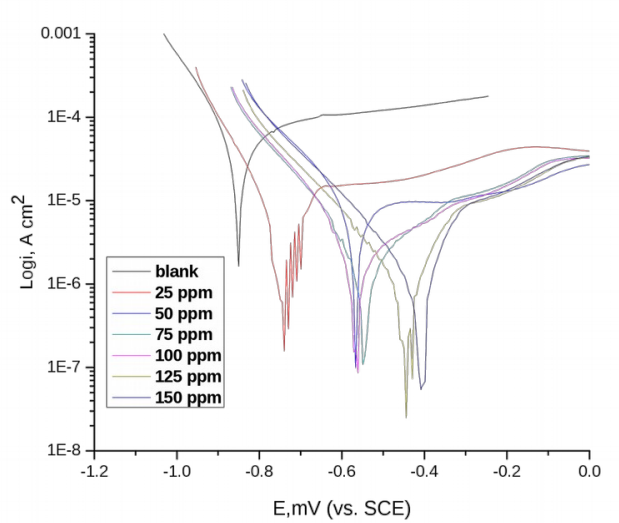

Figure (3): Potentiodynamic polarization curves for the corrosion of C-steel in $3.5 \% \mathrm{NaCl}$ in the absence and presence of various concentrations of compound (2) at $25^{\circ} \mathrm{C}$.

\subsection{Electrochemical impedance spectroscopy (EIS) measurements}

Surface properties and mechanism of corrosion inhibition can be obtained and examined from EIS diagrams [25-28]. EIS will detect $\mathrm{NaCl}$ solution and form a resistance solution $\left(R_{\mathrm{s}}\right)$. Once past that, the metal will form a passive layer which tends to be protective for their bond between Fe and functional groups of the investigated compounds. The thicker the passive layer than the value, the higher the Rct. Nyquist and Bode diagrams in the presence and absence of different concentrations of both compounds in $3.5 \% \mathrm{NaCl}$ solution are shown in Figures 4a, $4 \mathrm{~b}, 5 \mathrm{a}$ and $5 \mathrm{~b}$ respectively, it is observed that Nyquist plots give semicircles due to surface roughness, impurities and inhomogeneity of electrode surface [29-31]. To analyse the obtained data from EIS measurement an equivalent circuit used as shown in Figure 6 which present charge transfer reaction. Data of capacitance double layer (Cdl) can be measured from parameter $\mathrm{CPE}$ data $\mathrm{Y0}$ and $\mathrm{n}$ utilized the expression [32] as shown in equation (4):

$\mathrm{Cdl}=\mathrm{Y}_{0}\left(\omega_{\max }\right)^{\mathrm{n}-1}$

Where $\omega_{\max }$ is the angular frequency at which the imaginary component of the impedance reaches its maximum data, $\omega_{\max }=2 \pi \mathrm{f}_{\max }, \mathrm{f}_{\max }$ is the maximum frequency, $\mathrm{n}$ is the deviation parameter of the CPE: $-1 \leq n \leq 1$ and $Y_{o}$ is magnitude of the CPE. Different electrochemical parameters are shown in table 4

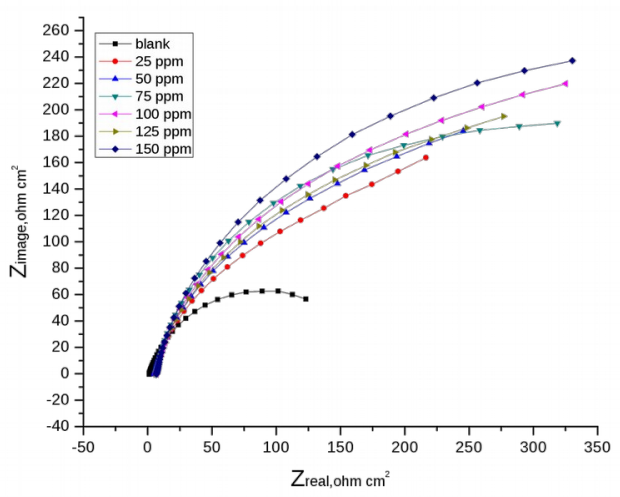

Fig. 4a: The Nyquist plots for corrosion of CS in $3.5 \% \mathrm{NaCl}$ solutions in the absence and presence of different concentrations of compound (1) at $25^{\circ} \mathrm{C}$.

Table (3): Data from potentiodynamic polarization of $\mathrm{C}$ steel in $3.5 \% \mathrm{NaCl}$ containing various concentrations of investigated compounds at $25^{\circ} \mathrm{C}$.

\begin{tabular}{|c|c|c|c|c|c|c|c|c|}
\hline Comp & $\begin{array}{l}\text { Conc., } \\
\text { ppm }\end{array}$ & $\begin{array}{l}\text { - } \mathrm{E}_{\text {corr, }} \mathrm{mV} \\
\text { (vs SCE) }\end{array}$ & $\begin{array}{c}\mathrm{i}_{\text {corr, }} \\
\mu \mathrm{A} \mathrm{cm}-2\end{array}$ & $\begin{array}{l}\text { C.R , } \\
\text { mpy }\end{array}$ & $\begin{array}{c}\beta_{\mathrm{c}} \\
\mathrm{mV} \text { dec }^{-1}\end{array}$ & $\begin{array}{c}\beta_{\mathrm{a}} \\
\mathrm{mV} \text { dec }^{-1}\end{array}$ & $\Theta$ & $\%$ IE \\
\hline Blank & ---- & 851 & 94.1 & 43 & 176 & 100 & --- & --- \\
\hline \multirow{6}{*}{1} & 25 & 806 & 52.1 & 36.1 & 212 & 110 & 0.446 & 44.6 \\
\hline & 50 & 828 & 46.9 & 29.4 & 197 & 112 & 0.502 & 50.2 \\
\hline & 75 & 754 & 43.3 & 29.3 & 217 & 120 & 0.540 & 54.0 \\
\hline & 100 & 753 & 36.1 & 28.8 & 188 & 123 & 0.616 & 61.6 \\
\hline & 125 & 679 & 30.5 & 27.5 & 276 & 115 & 0.675 & 67.6 \\
\hline & 150 & 780 & 27.7 & 25.7 & 221 & 123 & 0.706 & 70.6 \\
\hline \multirow{6}{*}{2} & 25 & 732 & 26.6 & 12.2 & 190 & 99 & 0.717 & 71.7 \\
\hline & 50 & 567 & 16.4 & 7.5 & 210 & 101 & 0.826 & 82.6 \\
\hline & 75 & 546 & 2.4 & 1.1 & 169 & 113 & 0.975 & 97.5 \\
\hline & 100 & 565 & 1.8 & 0.835 & 132 & 115 & 0.981 & 98.1 \\
\hline & 125 & 442 & 0.43 & 0.1965 & 134 & 113 & 0.995 & 99.5 \\
\hline & 150 & 406 & 0.411 & 0.188 & 121 & 118 & 0.996 & 99.6 \\
\hline
\end{tabular}


Table (4): EIS data of $\mathrm{C}$ steel in $3.5 \% \mathrm{NaCl}$ solutions in the absence and presence of different concentrations of investigated compounds at $25{ }^{\circ} \mathrm{C}$

\begin{tabular}{|c|c|c|c|c|c|}
\hline Comp & Conc., pm & $\mathrm{C}_{\mathrm{dl}}, \mathrm{x} 10^{3} \mu \mathrm{Fcm}^{-2}$ & $\mathbf{R}_{\mathrm{ct}}, \Omega \mathrm{cm}^{2}$ & $\grave{\mathbf{E}}$ & $\%$ IE \\
\hline Blank & 0 & 6.12 & 165.3 & --- & -- \\
\hline \multirow{6}{*}{1} & 25 & 2.73 & 371.5 & 0.555 & 55.50 \\
\hline & 50 & 2.41 & 421.1 & 0.607 & 60.74 \\
\hline & 75 & 2.25 & 449.7 & 0.632 & 63.24 \\
\hline & 100 & 2.18 & 465.3 & 0.645 & 64.47 \\
\hline & 125 & 2.01 & 504.5 & 0.672 & 67.23 \\
\hline & 150 & 1.81 & 559.1 & 0.704 & 70.43 \\
\hline \multirow{6}{*}{2} & 25 & 0.826 & 11800 & 0.986 & 98.60 \\
\hline & 50 & 0.666 & 15200 & 0.989 & 98.91 \\
\hline & 75 & 0.596 & 17100 & 0.990 & 99.03 \\
\hline & 100 & 0.557 & 18300 & 0.991 & 99.09 \\
\hline & 125 & 0.539 & 18900 & 0.991 & 99.12 \\
\hline & 150 & 0.508 & 20000 & 0.991 & 99.17 \\
\hline
\end{tabular}

Fig. 5b: The Bode plots for corrosion of Csteel in $3.5 \%$ $\mathrm{NaCl}$ solutions in the absence and presence of different concentrations of compound (2) at $25^{\circ} \mathrm{C}$

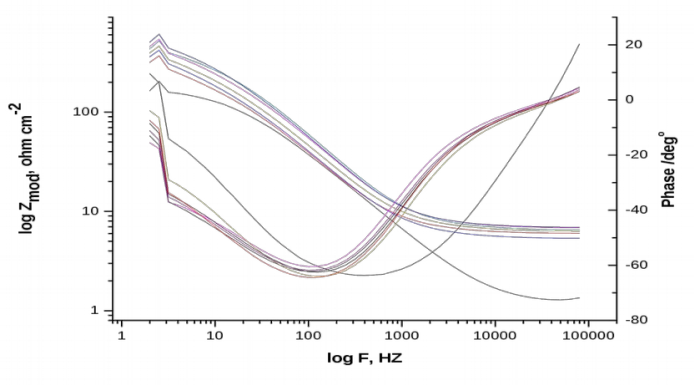

Fig. 4b: The Bode plots for corrosion of C-steel in $3.5 \% \mathrm{NaCl}$ solutions in the absence and presence of different concentrations of compound (1) at $25^{\circ} \mathrm{C}$

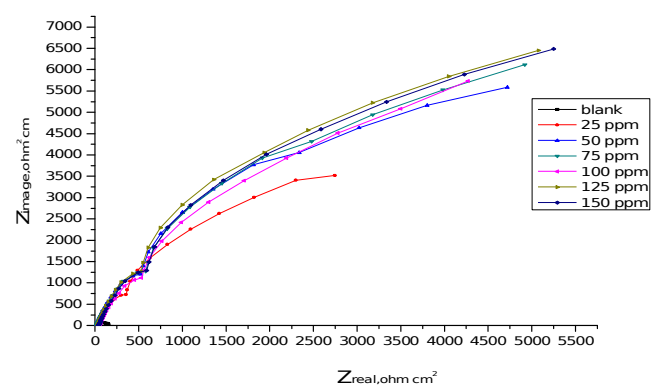

Fig. 5a: The Nyquist plots for corrosion of C-steel in $3.5 \% \mathrm{NaCl}$ solutions in the absence and presence of different concentrations of compound (2) at $25^{\circ} \mathrm{C}$

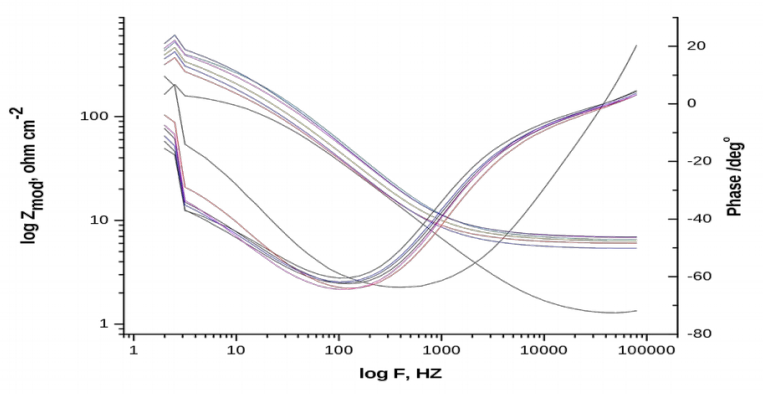

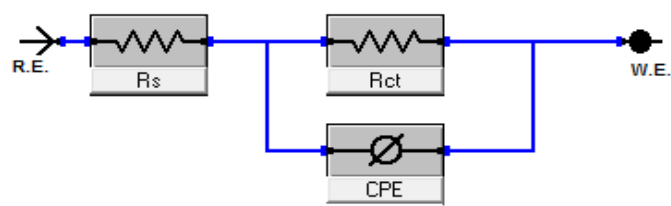

Figure 6: Equivalent electrical circuit model utilized to fit the results of impedance

The given data in Table 4 showed that $\mathrm{R}_{\mathrm{ct}}$ and \%IE increase by increasing compound concentration which is attributed to increase of the adsorbed layer thickness [33] it also shows that the relationship between $R_{\mathrm{ct}}$ and $C_{\mathrm{dl}}$ is inversely proportional. This occurs due to a decrease in local dielectric constantan or increasing the density of electric double layer. The presence of the investigated compounds modifies the structure of the electric double layer by adsorption compound molecules at the interface of a metal with a solution and the replacement of adsorbed water molecules by the inhibitor molecules. Adsorbed compounds on the metal surface forms a barrier layer to prevent mass transfer. With the addition of the compound concentration, the $R_{\mathrm{ct}}$ values increased, but the $C_{\mathrm{dl}}$ values tended to decrease. This is mainly due to the adsorption of compounds on the metal surface [34].

\subsection{Electrochemical frequency modulation (EFM) measurements}

EFM is the most convenient and suitable technique for online monitoring as it doesn $\mathrm{t}$ need to know Tafel slopes [35, 36], EFM spectra of c-steel in $3.5 \% \mathrm{NaCl}$ solution in the presence and absence of different 
BENZOIC ACID DERIVATIVES AS EFFECTIVE CORROSION ...

concentrations of both compounds are shown in Figures 7 \& 8. Different electrochemical parameters i.e. the corrosion density ( $\left.\mathrm{i}_{\text {corr }}\right)$, Tafel slopes $\left(\beta_{\mathrm{a}}, \beta_{\mathrm{c}}\right)$, causality factors (CF-2 and CF3 ) and \% IE for both compounds are shown in Table 5. The obtained data showed that both
$\Delta \mathrm{E}$ ) of the investigated compounds are shown in table 6. The difference $\Delta \mathrm{E}=\mathrm{E}_{\text {номо }}-\mathrm{E}_{\mathrm{Lumo}}$ is the energy required to move an electron from HOMO to LUMO. Low $\triangle \mathrm{E}$ facilitate adsorption of the molecule and thus will cause higher inhibition efficiency. The theoretical values of Eномо, ELUMo, $\mu$, $\Delta \mathrm{E}$ indicate that compound 2 $>$ compound 1. This support the

Figure 7: EFM for corrosion of C-steel in 3.5\% NaCl solution in the absence and presence of different concentrations of compound (1) at $25^{\circ} \mathrm{C}$

compounds are working as good corrosion inhibitors for c-steel corrosion in $3.5 \% \mathrm{NaCl}$ solution, as shown in Table 5, \% IE for both compounds increase with the increase of compound concentration, CF-2 and CF-3 values are close to the theoretical values 2 and 3 respectively which indicate the good quality of the obtained data.

\subsection{Quantum chemical calculations}

The reactive ability of the inhibitor is related to $\mathrm{E}_{\text {Hомо, }} \mathrm{E}_{\mathrm{LUMO}}$ [37]. Higher $\mathrm{E}_{\text {номо }}$ values indicate higher electron donating ability [38], but low $\mathrm{E}_{\text {Lumo }}$ indicates that the acceptor accepts electrons easily. The calculated quantum chemical indices ( $\mathrm{E}_{\text {Hомо }}, \mathrm{E}_{\mathrm{LuMO}}, \mu$, experimental results. 

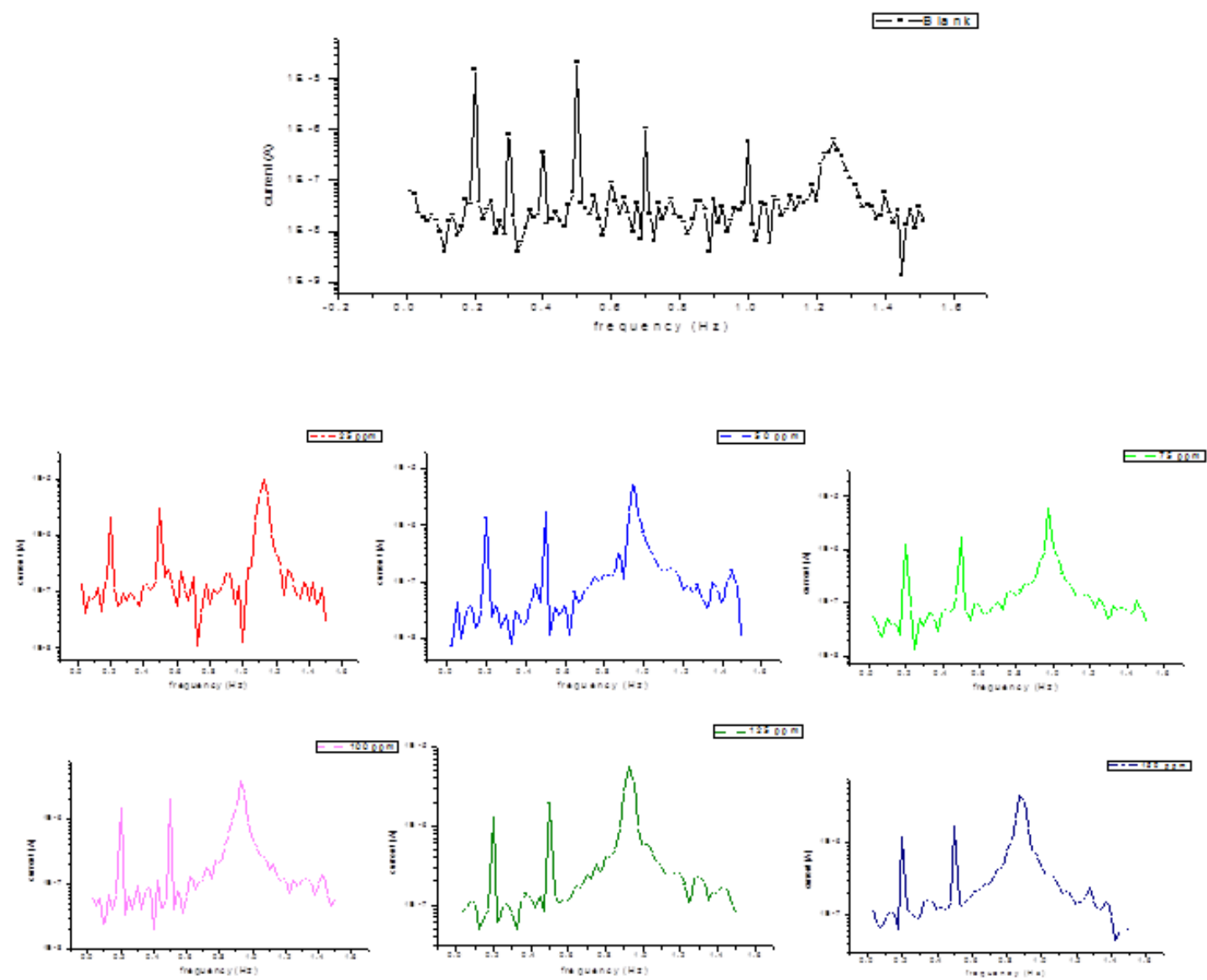

Figure 8: EFM for corrosion of C-steel in $3.5 \% \mathrm{NaCl}$ in the absence and presence of different Concentrations of compound (2) at $25^{\circ} \mathrm{C}$

Table (5): Electrochemical kinetic parameters obtained by EFM technique for C- steel in the absence and presence of various concentrations of investigated compounds in $3.5 \% \mathrm{NaCl}$ solution at $25 \circ \mathrm{C}$

\begin{tabular}{|c|c|c|c|c|c|c|c|c|c|}
\hline Comp & $\begin{array}{c}\text { Conc., } \\
\text { ppm }\end{array}$ & $\begin{array}{c}\mathbf{i}_{\text {corr }} \\
\boldsymbol{\mu A c m} \\
2\end{array}$ & $\begin{array}{c}\hat{\mathbf{a}}_{\mathrm{c}} \\
\mathbf{m V d e c}^{-1}\end{array}$ & $\begin{array}{c}\hat{\mathbf{a}}_{\mathbf{a}}, \\
\mathrm{mVdec}^{-} \\
{ }_{1}^{-}\end{array}$ & $\begin{array}{l}\text { C.R , } \\
\text { mpy }\end{array}$ & CF-2 & CF-3 & È & \%IE \\
\hline Blank & --- & 138 & 278.3 & 253 & 63.1 & 1.96 & 2.89 & -- & --- \\
\hline \multirow{6}{*}{1} & 25 & 76.5 & 198 & 318 & 31 & 2.06 & 2.98 & 0.445 & 44.5 \\
\hline & 50 & 65.3 & 223.2 & 306.2 & 29.8 & 1.968 & 3.12 & 0.527 & 52.7 \\
\hline & 75 & 59.6 & 193.6 & 280.1 & 27.2 & 1.75 & 3.16 & 0.568 & 56.8 \\
\hline & 100 & 54.5 & 158.1 & 212.8 & 24.9 & 2.12 & 3.01 & 0.605 & 60.5 \\
\hline & 125 & 51.7 & 149.3 & 276.9 & 23.6 & 2.01 & 3.26 & 0.625 & 62.5 \\
\hline & 150 & 41 & 139.6 & 209.9 & 18.8 & 2.01 & 2.83 & 0.703 & 70.3 \\
\hline \multirow{6}{*}{2} & 25 & 1.6 & 38.3 & 43.4 & 0.734 & 1.99 & 3.05 & 0.988 & 98.8 \\
\hline & 50 & 1.22 & 37.4 & 52.2 & 0.555 & 2.01 & 3.01 & 0.991 & 99.1 \\
\hline & 75 & 0.8693 & 35.5 & 39.5 & 0.0395 & 1.95 & 2.9 & 0.994 & 99.4 \\
\hline & 100 & 0.6437 & 22.02 & 23.9 & 0.0239 & 2.01 & 3.25 & 0.995 & 99.5 \\
\hline & 125 & 0.3923 & 15.2 & 16.7 & 0.0179 & 2.03 & 2.98 & 0.997 & 99.7 \\
\hline & 150 & 0.3013 & 12.3 & 13.5 & 0.0137 & 1.94 & 3.26 & 0.998 & 99.8 \\
\hline
\end{tabular}


RF.N7.OIC . AC.ID DF.RIVATIVF.S A.S F.FFF.CTIVF. CORROSION ...

Table (6): The calculated quantum chemical parameters for the investigated compounds using (PM3) method.

\begin{tabular}{|c|c|c|}
\hline Compound & 1 & 2 \\
\hline- Еномо $_{\text {но }}$ & 0.29542 & 0.29245 \\
\hline$-E_{\text {LUмо }}$ & 0.20606 & 0.20364 \\
\hline$\Delta \mathrm{E}$ & 0.09360 & 0.08881 \\
\hline$\mu$ & 4.125 & 4.178 \\
\hline
\end{tabular}

Different

Table (7): Molecular structure of compounds (1 and 2), and their frontier molecular orbital density distribution (HOMO and LUMO)

\begin{tabular}{|l|l|l|l|}
\hline & \multicolumn{2}{|c|}{1} & \\
\hline HOMO & & & \\
\hline
\end{tabular}

\section{Mechanism of inhibition.}

Inhibition of c-steel corrosion in $3.5 \%$ $\mathrm{NaCl}$ solution in the presence of prepared acryloyl chloride derivatives depends on adsorption of the investigated compound molecules on c-steel surface through interaction of $\pi$ electrons with the metal and through unshared electrons on heteroatom. The two compounds are the same and contain the same heteroatoms, but the substituted $\mathrm{COOH}$ group in compound 2 in the p-position and in compound 1 in the o-position., So, it may form with $\mathrm{NH}$ bond and mask the centres $\mathrm{NH}$ and $\mathrm{C}=\mathrm{O}$, so compound 1 has lesser active centres and molecular areas than compound 2. So, compound 1 has lesser \%IE than compound 2.

\section{CONCLUSIONS}

electrochemical (PP, EIS and EFM) measurements were carried out and proved that the investigated acrylic acid derivative corrosion compounds are good compounds for c-steel corrosion in $3.5 \% \mathrm{NaCl}$ solution. Inhibition efficiency (\%IE) increases with the increase of compound concentration. PP proved that the investigated compounds are of mixed type inhibitors while causality factors of EFM spectra proved the good quality of the obtained data. The highest efficiency occurs during addition of $150 \mathrm{ppm}$ of compound 2 to reach $99.5 \%$. The mechanism of inhibition that occurs through adsorption of compound molecules on the metal surface to form a thin protective layer. The theoretical values of $\mathrm{E}_{\text {номо, }} \mathrm{E}_{\text {Luмо, }} \mu, \Delta \mathrm{E}$ indicate that compound $2>$ 
compound 1 . This support the experimental results. The order of \%IE of the compounds is: compound $2>$ compound 1

\section{REFERENCES}

1. El-Haddad, M. N. (2013). Chitosan as a green inhibitor for copper corrosion in acidic medium. International journal of biological macromolecules, 55, 142-149.D. Jones, Principles and Prevention of Corrosion, Macmillan,New York, NY, USA, 1992.

2. Jones, D. A. (1992). Principles and prevention of corrosion. Macmillan.

3. Eddy, N. O. (2010). Part 3. Theoretical study on some amino acids and their potential activity as corrosion inhibitors for mild steel in HCl. Molecular Simulation, 36(5), 354-363.

4. Eddy, N. O., \& Mamza, P. A. P. (2009). Inhibitive and adsorption properties of ethanol extract of seeds and leaves of Azadirachta indica on the corrosion of mild steel in H2SO4. Portugaliae Electrochimica Acta, 27(4), 443-456.

5. Aytac, A., Özmen, Ü. \& Kabasakaloğlu, M. (2005). Investigation of some Schiff bases as acidic corrosion of alloy AA3102. Materials Chemistry and Physics, 89(1), 176-181.

6. Rodriguez-Valdez, L. M., Martínez-Villafañe, A., \& Glossman-Mitnik, D. (2005). Computational simulation of the molecular structure and properties of heterocyclic organic compounds with possible corrosion inhibition properties. Journal of Molecular Structure: THEOCHEM, 713(1), 65-70.

7. Benabdellah, M., Hammouti, B., Warthan, A., Al-Deyab, S. S., Jama, C., Lagrenée, M., \& Bentiss, F. (2012). 2, 5-Disubstituted 1, 3, 4oxadiazole derivatives as effective inhibitors for the corrosion of mild steel in 2M H 3 PO 4 solution. Int J Electrochem Sci, 7(4), 3489-3500.

8. Raj, X. J., \& Rajendran, N. (2012). Effect of some oxadiazole derivatives on the corrosion inhibition of brass in natural seawater. Journal of materials engineering and performance, 21(7), 1363-1373.

9. Seifzadeh, D., Basharnavaz, H., \& Bezaatpour, A. (2013). A Schiff base compound as effective corrosion inhibitor for magnesium in acidic media. Materials Chemistry and Physics, 138(2), 794-802.

10. Behpour, M., Ghoreishi, S. M., Mohammadi, N., Soltani, N., \& Salavati-Niasari, M. (2010). Investigation of some Schiff base compounds containing disulfide bond as $\mathrm{HCl}$ corrosion inhibitors for mild steel. Corrosion Science, 52(12), 4046-4057.
11. Chetouani, A., \& Hammouti, B. (2003). Corrosion inhibition of iron in hydrochloric acid solutions by naturally henna. Bulletin of electrochemistry, 19(1), 23-25.

12. Bouklah, M., Hammouti, B., Aouniti, A., \& Benhadda, T. (2004). Thiophene derivatives as effective inhibitors for the corrosion of steel in $0.5 \mathrm{MH} 2 \mathrm{SO} 4$. Progress in organic coatings, 49(3), 225-228.

13. Elewady, G. Y. (2008). Pyrimidine derivatives as corrosion inhibitors for carbon-steel in $2 \mathrm{M}$ hydrochloric acid solution. Int. J. Electrochem. Sci, 3(10), 1149.

14. Zaafarany, I., \& Abdallah, M. (2010).

Ethoxylated fatty amide as corrosion inhibitors for carbon steel in hydrochloric acid solution. Int J Electrochem Sci, 5, 18-28.

15. Yurt, A., Balaban, A., Kandemir, S. U., Bereket, G., \& Erk, B. (2004). Investigation on some Schiff bases as $\mathrm{HCl}$ corrosion inhibitors for carbon steel. Materials Chemistry and Physics, 85(2), 420-426..

16. Fouda, A. S., Attia, A. A., \& Negm, A. A. (2014). Some thiophene derivatives as corrosion inhibitors for carbon steel in hydrochloric acid. Journal of Metallurgy, 2014.

17. Ju, H., Kai, Z. P., \& Li, Y. (2008). Aminic nitrogen-bearing polydentate Schiff base compounds as corrosion inhibitors for iron in acidic media: a quantum chemical calculation. Corrosion Science, 50(3), 865-871.

18. Gopi, D., Govindaraju, K. M., \& Kavitha, L. (2010). Investigation of triazole derived Schiff bases as corrosion inhibitors for mild steel in hydrochloric acid medium. Journal of Applied Electrochemistry, 40(7), 1349-1356.

19. Migahed, M. A., Abdul-Raheim, A. M., Atta, A. M., \& Brostow, W. (2010). Synthesis and evaluation of a new water soluble corrosion inhibitor from recycled poly (ethylene terphethalate). Materials chemistry and physics, 121(1), 208-214.

20. Singh, A. K., \& Quraishi, M. A. (2010). Inhibiting effects of 5-substituted isatin-based Mannich bases on the corrosion of mild steel in hydrochloric acid solution. Journal of Applied Electrochemistry, 40(7), 1293-1306.

21. Obot, I. B., Obi-Egbedi, N. O., \& Odozi, N. W. (2010). Acenaphtho [1, 2-b] quinoxaline as a novel corrosion inhibitor for mild steel in 0.5 MH 2 SO 4. Corrosion Science, 52(3), 923926.

22. Obot, I. B., \& Obi-Egbedi, N. O. (2010). Indeno-1-one [2, 3-b] quinoxaline as an effective inhibitor for the corrosion of mild 
BENZOIC ACID DERIVATIVES AS EFFECTIVE CORROSION ...

steel in $0.5 \mathrm{MH} 2 \mathrm{SO} 4$ solution. Materials Chemistry and Physics, 122(2), 325-328.

23. Noor, E. A. (2009). Evaluation of inhibitive action of some quaternary $\mathrm{N}$-heterocyclic compounds on the corrosion of $\mathrm{Al}-\mathrm{Cu}$ alloy in hydrochloric acid. Materials Chemistry and Physics, 114(2), 533-541.

24. Shukla, S. K., Singh, A. K., \& Ebenso, E. E. (2011). Pharmaceutically active compound as corrosion inhibitor for mild steel in acidic medium. International Journal of Electrochemical Science, 6, 4276-4285.

25. Bentiss, F., Outirite, M., Traisnel, M., Vezin, H., Lagrenée, M., Hammouti, B., \& Jama, C. (2012). Improvement of corrosion resistance of carbon steel in hydrochloric acid medium by 3, 6-bis (3-pyridyl) pyridazine. Int. $J$. Electrochem. Sci, 7, 1699-1723.

26. J.Marsh, Advanced Organic Chemistry, 3rd edn. (Wieley Eastern, New Delhi), 1988.

27. Silverman, D. C., \& Carrico, J. E. (1988). Electrochemical impedance technique-a practical tool for corrosion prediction. Corrosion, 44(5), 280-287.

28. AitHaddou, B., Chebabe, D., Dermaj, A., Benassaoui, H., El Assyry, A., Hajjaji, N., \& Srhiri, A. Comparative study of low carbon steel corrosion inhibition in $1 \mathrm{M} \mathrm{HCl}$ by 1,2 , 4triazole-5-thione derivatives.

29. Benali, O., Larabi, L., Traisnel, M., Gengembre, L., \& Harek, Y. (2007). Electrochemical, theoretical and XPS studies of 2-mercapto-1-methylimidazole adsorption on carbon steel in $1 \mathrm{M} \mathrm{HClO} \mathrm{4.} \mathrm{Applied} \mathrm{surface}$ science, 253(14), 6130-6139.

30. Lorenz, W. J., \& Mansfeld, F. (1981). Determination of corrosion rates by electrochemical DC and AC methods. Corrosion Science, 21(9-10), 647-672.

31. Bodaghi, A., \& Hosseini, J. (2012). Corrosion Behavior of Electrodeposited Cobalt-Tungsten Alloy Coatings in $\mathrm{NaCl}$ Aqueous Solution. Int. J. Electrochem. Sci, 7, 2584-2595.

32. Hsu, C. H., \& Mansfeld, F. (2001). Concerning the conversion of the constant phase element parameter $\mathrm{Y} 0$ into a capacitance. Corrosion, 57(9), 747-748.

33. Epelboin, I., Keddam, M., \& Takenouti, H. (1972). Use of impedance measurements for the determination of the instant rate of metal corrosion. Journal of Applied Electrochemistry, 2(1), 71-79.

34. Pradityana, A., Shahab, A., Noerochim, L., \& Susanti, D. (2016). Inhibition of Corrosion of Carbon Steel in 3.5\% NaCl Solution by
Myrmecodia Pendans Extract. International Journal of Corrosion, 2016.

35. Kuş, E., \& Mansfeld, F. (2006). An evaluation of the electrochemical frequency modulation (EFM) technique. Corrosion Science, 48(4), 965-979.

36. Abdallah, M., Helal, E. A., \& Fouda, A. S. (2006). Aminopyrimidine derivatives as inhibitors for corrosion of 1018 carbon steel in nitric acid solution. Corrosion Science, 48(7), 1639-1654.

37. Lee, C., Yang, W., \& Parr, R. G. (1988). Development of the Colle-Salvetti correlationenergy formula into a functional of the electron density. Physical review B, 37(2), 785.

38. Issa, R. M., Awad, M. K., \& Atlam, F. M. (2008). Quantum chemical studies on the inhibition of corrosion of copper surface by substituted uracils. Applied Surface Science, 255(5), 2433-2441. 